\title{
TRANSFORMAÇÕES NA PAISAGEM DO NORTE PARANAENSE: DE 1950 A 1980
}

Liriani de Lima Santos

Universidade Estadual de Maringá - UEM Maringá, PR, Brasil liri li@hotmail.com

\begin{abstract}
RESUMO
A pesquisa tem como objetivo retratar por meio de levantamentos bibliográficos, registros fotográficos e entrevistas, aspectos do processo de ocupação e povoamento do Norte do Paraná, no que se refere aos elementos materiais da paisagem: traçado dos lotes rurais e urbanos, tipo de construção de moradias, comércios, igrejas e demais equipamentos urbanos e rurais. $O$ trabalho aponta ainda os resquícios deste momento de extrema relevância para o estado e que está estreitamente ligado ao ciclo econômico do café. Na atualidade estes marcos da colonização Norte paranaense se esmaecem na paisagem, consequência das transformações ocasionadas pelo processo de modernização do campo.
\end{abstract}

Palavras-chave: Geografia Cultural. Colonização. Paraná. Paisagem.

\section{TRANSFORMATIONS IN THE NORTH PARANAENSE LANDSCAPE: 1950 TO 1980}

\begin{abstract}
The research aims to portray, through bibliographical surveys, photographic records and interviews, aspects of the occupation and settlement process of the North of Paraná, regarding the material elements of the landscape: layout of rural and urban lots, type of construction of housing, commerce, churches and other urban and rural facilities. The work also points to the remnants of this moment of extreme relevance to the state and that is closely linked to the coffee economic cycle. At the present time these landmarks of the North paranaense colonization fade in the landscape, consequence of the transformations occasioned by the process of modernization of the field.
\end{abstract}

Keywords: Cultural Geography. Colonization. Paraná. Landscape.

\section{INTRODUÇÃO}

Embora exista um número elevado de estudos geográficos que tomam por referência o Norte do Paraná a pesquisa desenvolvida traz como contribuição uma análise por meio do viés da Geografia Cultural, pois a apreciação de fatos geográficos calcadas unicamente em aspectos econômicos, políticos e/ou sociais limitam a investigação e não são eficazes em esclarecer as intensas alterações do espaço geográfico que se evidenciam na paisagem.

Sauer (2003, p. 22-23) ao tratar da Geografia Cultural esclarece:
A Geografia Cultural se interessa, portanto, pelas obras humanas que se inscrevem na superfície terrestre e imprimem uma expressão característica [...] 0 desenvolvimento da Geografia Cultural procede necessariamente da reconstrução de sucessivas culturas de uma área, começando pela cultura original e continuando até o presente.

A pesquisa tem como objetivo retratar por meio de levantamentos bibliográficos, registros fotográficos e entrevistas, aspectos do processo de ocupação e povoamento do Norte do Paraná, mais especificamente da área abrangida pela colonização realizada pela Companhia de Terras Norte do

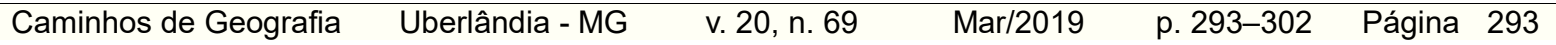


Paraná (CTNP). A CTNP - de origem inglesa - passou para o controle nacional em 1944, mudando sua denominação para Companhia Melhoramentos Norte do Paraná (CMNP) em 1951. No trabalho serão adotas as duas siglas (CTNP/CMNP), pois durante o período de formação dos municípios estudados a empresa esteve tanto sob o controle inglês quanto brasileiro.

Foram realizadas ao todo quarenta entrevistas semiestruturadas com personagens que vivenciaram o período em que predominava a cultura cafeeira e atores sociais da atualidade. A pesquisa embora se refira o Norte do Paraná, ocorreu apenas em três municípios colonizados pela referida companhia, a saber: São Jorge do Ivaí, Terra Boa e Jussara, a escolha deu-se pelo fato de os municípios serem representativos das transformações ocorridas no Norte paranaense desde a fundação das primeiras cidades até a atualidade.

De acordo com a estimativa da população de julho de 2016, divulgada pelo IBGE, os municípios possuíam conjuntamente 29.557 habitantes, com área total de 846.807 quilômetros quadrados. Em ambos os municípios a fertilidade do solo foi um dos principais fatores atrativos aos migrantes que, na grande maioria, se estabeleceram na zona rural, dando início ao cultivo do café, que por cerca de três décadas foi o principal produto agrícola e sustentáculo da economia.

Surgidos entre meados de 1940 até o início de 1950, os municípios tiveram suas terras divididas, demarcadas e comercializadas pela CTNP/CMNP e logo foram adquiridas por compradores procedentes do estado de São Paulo (Alta Sorocabana, principalmente), Minas Gerais e Bahia. A toponímia faz menção aos recursos naturais disponíveis, como o principal rio da bacia hidrográfica (Ivaí), para o município de São Jorge do Ivaí, uma espécie de palmeira (Euterpe edulis), para o município de Jussara, ou o tipo de solo (Latossolo vermelho), para o município de Terra Boa. A figura 1 mostra a localização dos municípios.

Figura 1 - Localização da área de estudo.

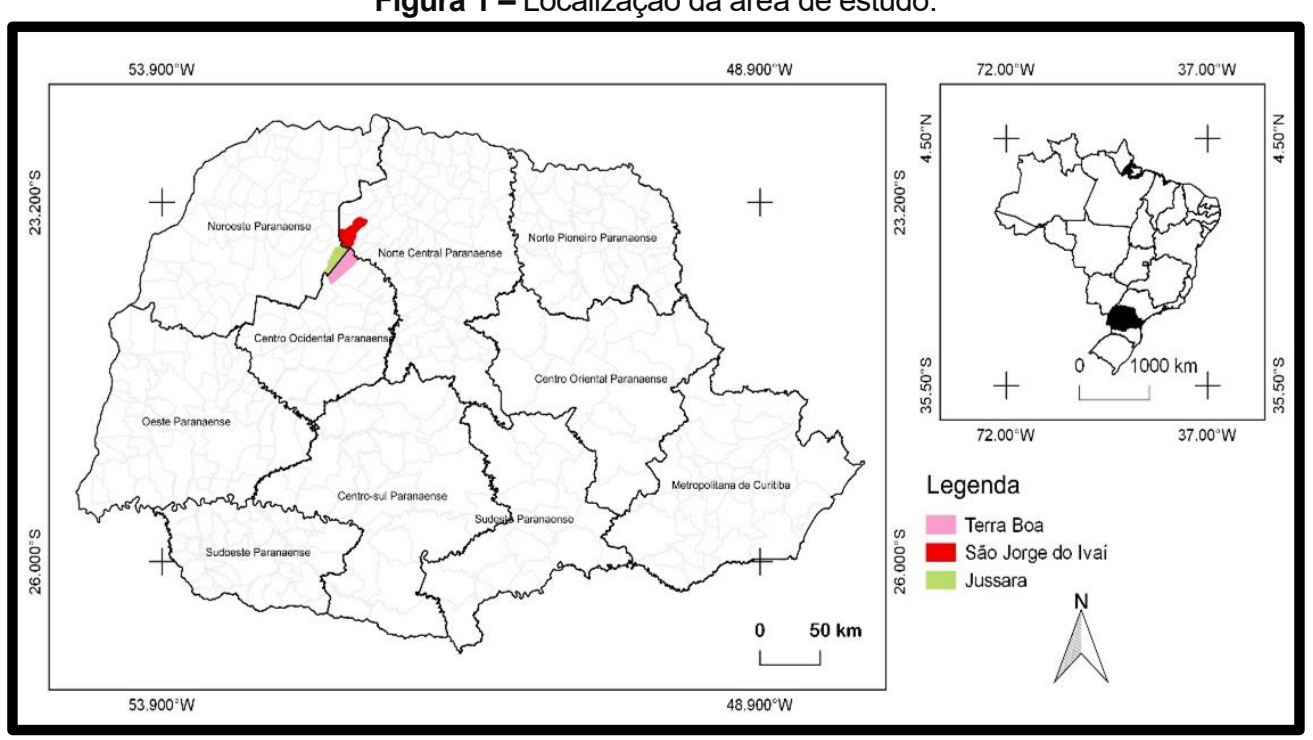

Fonte - IBGE (2017).

As transformações impingidas na paisagem do Norte paranaense no início de sua colonização estão profundamente atreladas à ação da companhia colonizadora que atuou na região e a hegemonia da economia cafeeira, estes fatos contribuíram para uma organização espacial bastante peculiar e que ainda hoje pode ser notada tanto na paisagem urbana quanto rural da região.

\section{A PRESENÇA DA CTNP/CMNP NO NORTE PARANAENSE}

Em fins do século XIX e início do século XX, mineiros e paulistas viram nas terras paranaenses novas possibilidades para a expansão da economia cafeeira. O governo do estado do Paraná põe as terras devolutas à disposição da ocupação permanente e permite assim, investimentos de companhias particulares de colonização. A presença marcante do estado na concessão de glebas com extensa área às empresas de colonização, e a atuação pontual dessas empresas na comercialização posterior de lotes destinados às atividades agrícolas, contribuíram para a organização da estrutura agrária do Norte do Paraná, sustentada em pequenas propriedades. Quando falamos de projeto de colonização e sua eficácia, nos referimos a Companhia de Terras Norte do Paraná (CTNP), e posteriormente a Companhia Melhoramentos Norte do Paraná (CMNP), que substituiu a primeira. 
Ambas proporcionaram uma colonização extremamente planejada. Para Monbeig (1984) e Luz (1997) a ocupação do Norte do Paraná não se deu de forma uniforme e ao mesmo tempo.

Conforme a época e a origem da respectiva colonização o Norte do Paraná pode ser dividido em três áreas: o Norte Velho, que vai da divisa nordeste com São Paulo até Cornélio Procópio, colonizado entre 1860 e 1925 por elementos paulistas e mineiros; o Norte Novo, delimitado pelos rios Tibagi, Ivaí e Paranapanema, colonizado entre 1920 e 1950; o Norte Novíssimo, que se estende do rio Ivaí ao rio Paraná e ao Piquiri, colonizado desde 1940 até 1960 (LUZ, 1997, p. 17).

Na figura 2 é possível visualizar as três áreas em que o Norte do estado é divido: Norte Velho, Norte Novo e Norte Novíssimo. Ainda é apontado o Paraná Tradicional, área de colonização mais antiga, iniciada no século XVII e o Oeste, cuja ocupação oficial originou-se em meados do século XX.

Figura 2 - Áreas de colonização do Paraná.

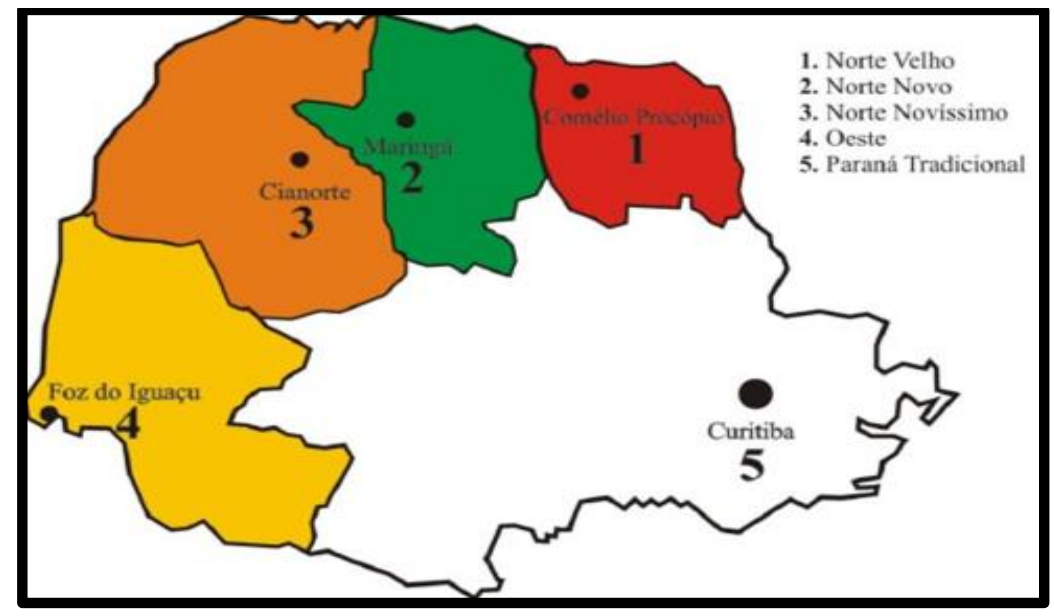

Fonte - Luz (1997). Organização - A autora (2011).

O planejamento da Companhia Melhoramentos é visível na paisagem dos municípios do Norte paranaense. Ao referir-se à divisão dos lotes rurais, Wachowicz (2001, p. 270) descreve que:

\section{[...] eram traçados em forma de longos retângulos, tendo quase todos frente para uma estrada e fundos para um regado ou rio. Desta forma, a estrada sempre passava nas regiões mais elevadas e todos os lotes ficavam inclinados.}

A figura 3 apresenta o sistema de repartição dos lotes rurais realizado pela CTNP/CMNP, nela é possível visualizar o formato retangular dos lotes. Esse tipo de planejamento oportunizava aos proprietários o acesso a um rio - fundamental para prover água aos animais - e a uma estrada principal. A casa e demais equipamentos como tulhas, paióis, hortas, galinheiros e pasto ficavam na parte mais inferior do lote, considerada imprópria ao cultivo do café, tanto por ser mais acidentada quanto por ser mais atingida pelas geadas.

Figura 3 - Repartição dos lotes rurais realizada pela CTNP/CMNP.

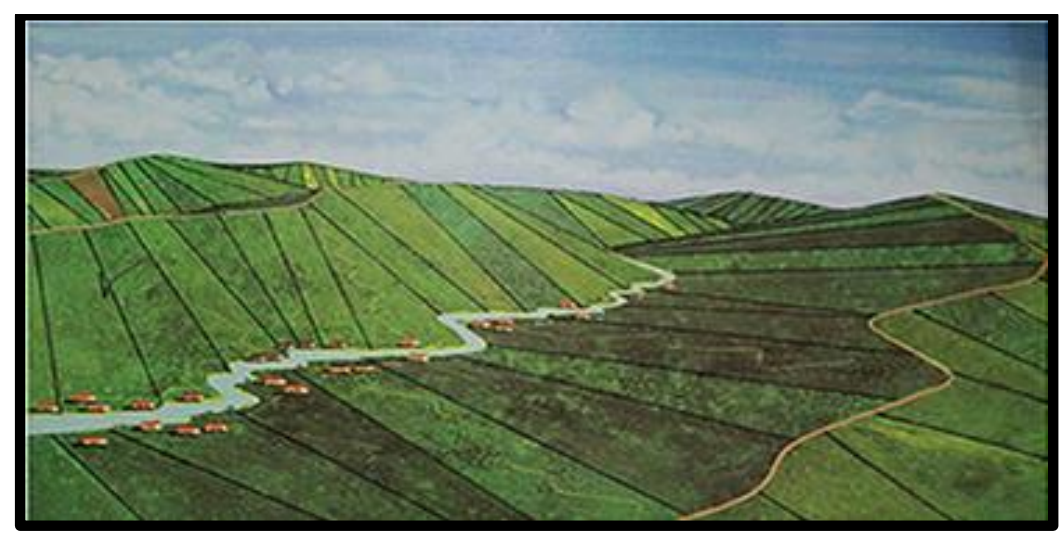

Fonte - CMNP (1975). 
A dimensão dos lotes ficava em torno de 5 a 15 alqueires paulistas (10 a 30 hectares, aproximadamente), formando então, uma estrutura sustentada sobre pequenas propriedades rurais. A venda e aquisição dos lotes de terras ocorriam da seguinte forma:

\begin{abstract}
[...] visitavam as glebas disponíveis e escolhiam seu lote, regressando logo para fechar o negócio e pagar os dez por cento exigidos para assegurar a posse da propriedade. Dentro de sessenta dias [...] mais vinte por cento [...] o restante pago em quatro anos: dez por cento ao fim do primeiro ano, quantia essa módica por ser o ano de abertura da propriedade, e vinte por cento no final de cada um dos três anos seguintes. Os juros não ultrapassavam oito por cento ao ano (CMNP, 1975, p. 124).
\end{abstract}

Após a venda do lote rural, dava-se início a ocupação pelos compradores que basicamente assim procediam:

Instalava-se provisoriamente um rancho feito com folhas de palmeiras e [...] (iniciavam a derrubada da mata). À derrubada seguia-se a queima, a coveação e o plantio do café. Nas ruas [do café] plantavam-se cereais, à volta do rancho plantava-se árvores frutíferas, à beira d'água plantava-se capim para os animais. Iniciava-se a criação de porcos e galinhas (CMNP, 1975, p. 124).

Embora tanto o processo de colonização como a ação das companhias colonizadoras sejam alardeados como pacíficos, estruturados, bem sucedidos e até mesmo benevolentes, por favorecerem a aquisição de terras por pequenos agricultores, alguns estudos, embora escassos, tratam a respeito das populações que viviam nas terras do Norte paranaense antes da ocupação oficial, e mostram que essa ocupação não foi tão pacífica quanto aparentemente se propagandeia, é o que retratam autores como TOMAZI (1999) e HARTUNG (2000).

A presença da CTNP/CMNP foi de fundamental importância para os municípios do Norte paranaense, cujas terras foram predominantemente incorporadas por meio de pequenas propriedades rurais. $\mathrm{O}$ proprietário e a família eram responsáveis por todo o trabalho no lote. O cultivo do café era a principal fonte de renda, mas enquanto não produzisse entre suas ruas eram cultivados produtos diversos destinados tanto "para o gasto" como para a comercialização na cidade. A pecuária era quase inexistente devido à pequena área dos lotes. Dessa forma, desenvolvia-se a criação de suínos e aves cujo destino era o mesmo dado aos cultivos realizados entre os pés de café.

Quanto aos lotes nas cidades, estes obedeceram a um plano urbanístico que se valeu das características do relevo com divisão em datas de terras destinadas a construção de residências e comércios, todos eles circundados por um cinturão verde subdividido em chácaras com o intuito de abastecer a população.

A companhia projetou cidades cerca de $100 \mathrm{~km}$ distantes umas das outras como Londrina, Maringá, Cianorte e Umuarama (figura 4). Entre elas foram fundados centros urbanos menores, distantes aproximadamente $15 \mathrm{Km}$ um dos outros e entre eles foram criados os patrimônios, povoados cuja função era a de abastecedores intermediários para uma numerosa população rural.

Figura 4 - Terras colonizadas pela CTNP/CMNP.

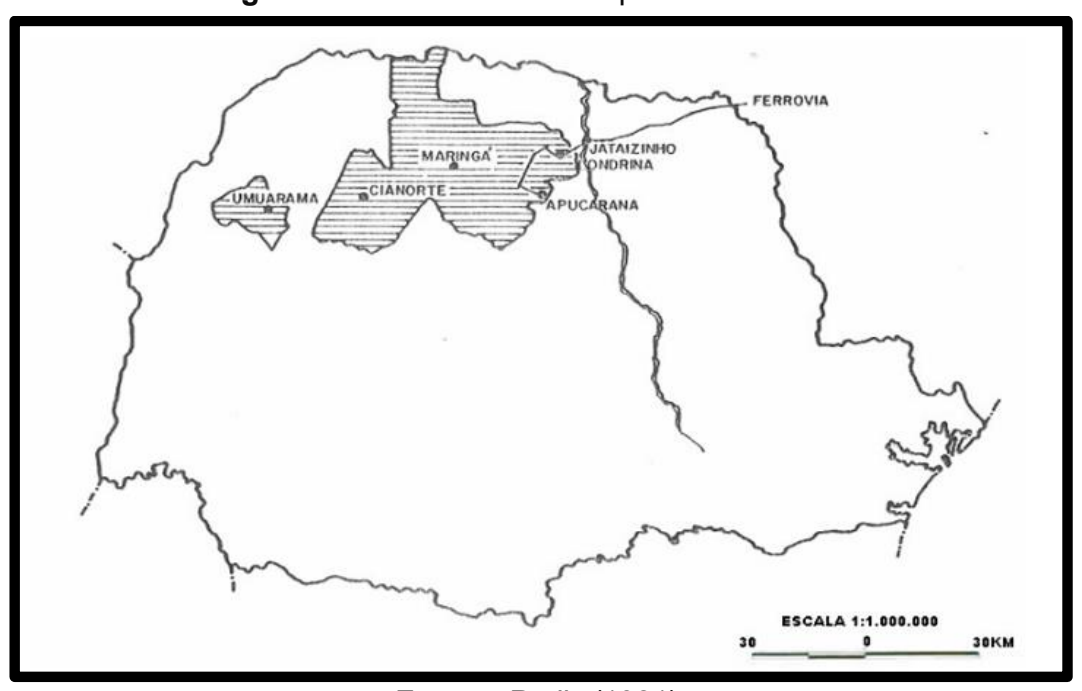

Fonte - Padis (1981). 
O acesso às cidades era dificultado pelas condições das estradas, principalmente durante e logo após as chuvas. Diante disso, por iniciativas particulares, pequenas mercearias, mais conhecidas como "vendas", eram instaladas ao longo das estradas rurais.

Neste tipo de estabelecimento vários produtos eram comercializados indo de mantimentos a ferramentas para o trabalho (enxadas, arados, entre outros) e miudezas em geral. Segundo relatos coletados durante entrevistas com moradores que vivenciaram o processo de ocupação e povoamento do Norte do Paraná, essas vendas possuíam uma peculiaridade que também se encontrava nos estabelecimentos comerciais encontrados nas cidades, aí denominados "secos e molhados". Os produtos ficavam em prateleiras atrás do balcão. Os pedidos eram feitos a um dos vendedores, que seguia anotando e trazendo as mercadorias. O preço dos produtos era sabido de cabeça pelo vendedor que marcava o produto e o respectivo valor em uma caderneta. Ao final, faziase a soma e anunciava-se o valor total, que poderia ser pago à vista ou em determinado período: o final do mês ou o término da colheita, sendo esta última modalidade de pagamento a mais utilizada.

\title{
A PAISAGEM REVISITADA
}

No Brasil, o interesse pela Geografia Cultural vem aumentando e pode ser confirmado pela quantidade de trabalhos apresentados nos mais diversos eventos em Geografia, nos artigos publicados em periódicos científicos e nas dissertações e teses apresentadas nos programas de pós-graduação. Tal fato possivelmente tem ocorrido pela percepção de que a análise de fatos geográficos calcada unicamente em aspectos econômicos, políticos e/ou sociais tende a limitar a investigação e não dão conta de esclarecer as intensas transformações do espaço geográfico que se evidenciam na paisagem. De acordo com McDowell (1996, p.159):

\begin{abstract}
A geografia cultural é atualmente uma das mais excitantes áreas de trabalho geográfico. Abrangendo desde as análises de objetos do cotidiano, representação da natureza na arte e em filmes até estudos do significado das paisagens e a construção social de identidades baseadas em lugares, ela cobre numerosas questões. Seu foco inclui a investigação da cultura material, costumes sociais e significados simbólicos, abordados a partir de uma série de perspectivas teóricas.
\end{abstract}

Por meio das indicações de Mc Dowell (1996), é possível perceber a variedade de temáticas que a Geografia Cultural possibilita analisar. Ao retrocedermos para os primórdios da Geografia, percebemos que sua vocação descritiva é nata, pois seus interesses mesmo antes de sua institucionalização acadêmica e científica sempre estiveram voltados para a descrição da diversidade da superfície terrestre. Sendo assim, os estudos que compreendem a relação espaço/paisagem e cultura são próprios da Geografia.

O conceito de paisagem é polissêmico recebendo diversas acepções conforme as diferentes correntes do pensamento geográfico se desenvolviam. Justamente devido ao seu caráter multidimensional abarcar a paisagem de forma completa, abrangendo todos os seus sentidos tornase impossível.

Os homens, por meio de suas ações, deixam marcas na paisagem. No intuito de suprir suas necessidades as sociedades têm despendido esforços para transformar o meio em que vivem, por meio de ferramentas e técnicas. Muitas culturas que já deixaram de existir podem ser estudadas por meio destas marcas, que se constituem em único instrumento de investigação, quando não há registros escritos ou quando não é mais possível o contato com membros do grupo, geralmente os mais velhos, que podem contribuir e enriquecer a investigação e o caminho de reconstrução por meio de seus relatos.

Assim, Claval (2014, p. 23) nos conta:

As paisagens constituem um objeto de estudo fascinante para aqueles que se interessam pela geografia cultural, mas sua interpretação nunca é fácil: falam dos homens que as modelam e que as habitam atualmente, e daqueles que lhes precederam; informam sobre as necessidades e os sonhos de hoje, e sobre os de um passado muitas vezes difícil de determinar. 
Vemos assim que a paisagem não é simplesmente um espaço natural, mas o lugar onde os indivíduos estabelecem sua própria organização do espaço e do tempo, ela não surge ao acaso, mas é criada formal ou informalmente. Para ser estudada não necessita ser rara ou monumental: as paisagens atuais são carregadas de história e refletem costumes locais, a visão de mundo e as relações de produção de determinada sociedade, podem ser, portanto, alvos de estudo.

\begin{abstract}
Cada período se caracteriza por um dado conjunto de técnicas. Em cada período histórico temos um conjunto próprio de técnicas e de objetos correspondentes. Num momento $B$, muitos elementos do momento $A$ permanecem; e surgem novos. É a inovação triunfante que permite sair de um período e entrar em um outro. A inovação traz a modificação da paisagem, que passa a ter objetos dos momentos A e B (SANTOS, 1988, p. 21).
\end{abstract}

Percebe-se por meio de Santos (1988) que a paisagem não é estática ao contrário, ela é extremamente dinâmica, sendo construída e reconstruída ao longo do tempo.

Sauer (1983) também aponta a relevância dos elementos temporais e históricos para a geografia, que segundo ele intervém na relação homem/paisagem. A paisagem para Sauer $(1983 ; 2004)$ é formada pelo acúmulo de experiências humanas. As ações humanas estão expressas na paisagem que pode ser definida como "uma área composta por uma associação distinta de formas, ao mesmo tempo físicas e culturais". A paisagem cultural sofre transformações seja pelo desenvolvimento, seja pela substituição de culturas.

O trabalho do geógrafo seria similar ao de um detetive, investigando e buscando por meio de pistas (indícios materiais) reconstituir uma paisagem pretérita. Nesse sentido, o estudo de formas fósseis - ou ruínas - é de extrema relevância, pois, por meio delas é possível conhecer os lugares e o porquê determinados povos aí se estabeleceram. Nomes de lugares são representativos e podem revelar tradições e costume populares cuja chave de explicação os membros mais antigos do grupo ainda guardam.

Rapoport (1969) aponta que a partir de um exame de edifícios ou artefatos, quando já não existem registros escritos, e quando não pode haver um conhecimento detalhado de um modo de vida, os objetos podem nos contar grandes fatos sobre uma cultura.

Portanto, o geógrafo deve sempre questionar quais as origens do fato estudado, ao localizar determinadas atividades é preciso também conhecer o funcionamento da cultura e as formas de convivência do grupo, para isso é necessário à realização de uma reconstituição histórica. Geografia e história constituem-se disciplinas complementares; a geografia necessita da história para compreender acontecimentos passados e suas espacialidades e, ao mesmo tempo, os fatos passados contribuem sobremaneira para a formação das paisagens presentes.

Assim, ao levantar a história da ocupação oficial do Norte do Paraná percebe-se que as mesmas características descritas por Monbeig (1984) nas cidades das frentes pioneiras anteriores podiam ser percebidas: casas de madeira já consolidadas ou em construção, ruas sem pavimento, expressivo movimento de pessoas na cidade durante os finais de semana, quando a população rural buscava esse espaço para satisfazer suas necessidades de lazer e serviços.

Porém, para boa parte dos moradores da zona rural a vida social era limitada, novamente devido à dificuldade no transporte. Daí a importância da religião, fonte de coesão entre o grupo, responsável pela consolidação de uma sociedade relativamente homogênea que estabelecia relações sociais diversas, com costumes e modos de vida comuns.

As capelas funcionavam como ponto de encontro da população. Localizavam-se nas proximidades da venda, da escola e do campo de bocha ou de futebol, em uma disposição bastante semelhante às praças da zona urbana. Festas religiosas como quermesses, 
comemorações dos santos padroeiros, a reza do terço, entre outros eventos, marcavam uma vida comunitária bastante intensa tanto nas cidades quanto no campo. Para facilitar o acesso, nas cidades, a praça principal foi edificada no ponto mais elevado ou na parte central. As igrejas por sua vez, foram igualmente erigidas em locais de destaque: nas praças principais ou muito próximas, adjacentes à avenida principal (caso do município de Jussara). Esta disposição marcava também a importância e o poder da religião Católica na sociedade da época. A figura 5 apresenta a evolução das igrejas urbanas localizadas nos municípios de São Jorge do Ivaí, Terra Boa e Jussara.

Figura 5 - Evolução arquitetônica das igrejas matrizes dos municípios estudados. A) Primeira Igreja Católica localizada no município de São Jorge do Ivaí. B) Construção do templo atual. C) Construção vigente. D) Primeira Igreja Católica localizada no município de Terra Boa. E) Construção do templo atual. F) Construção vigente. G) Primeira Igreja Católica localizada no município de Jussara. H) Construção do templo atual. I)

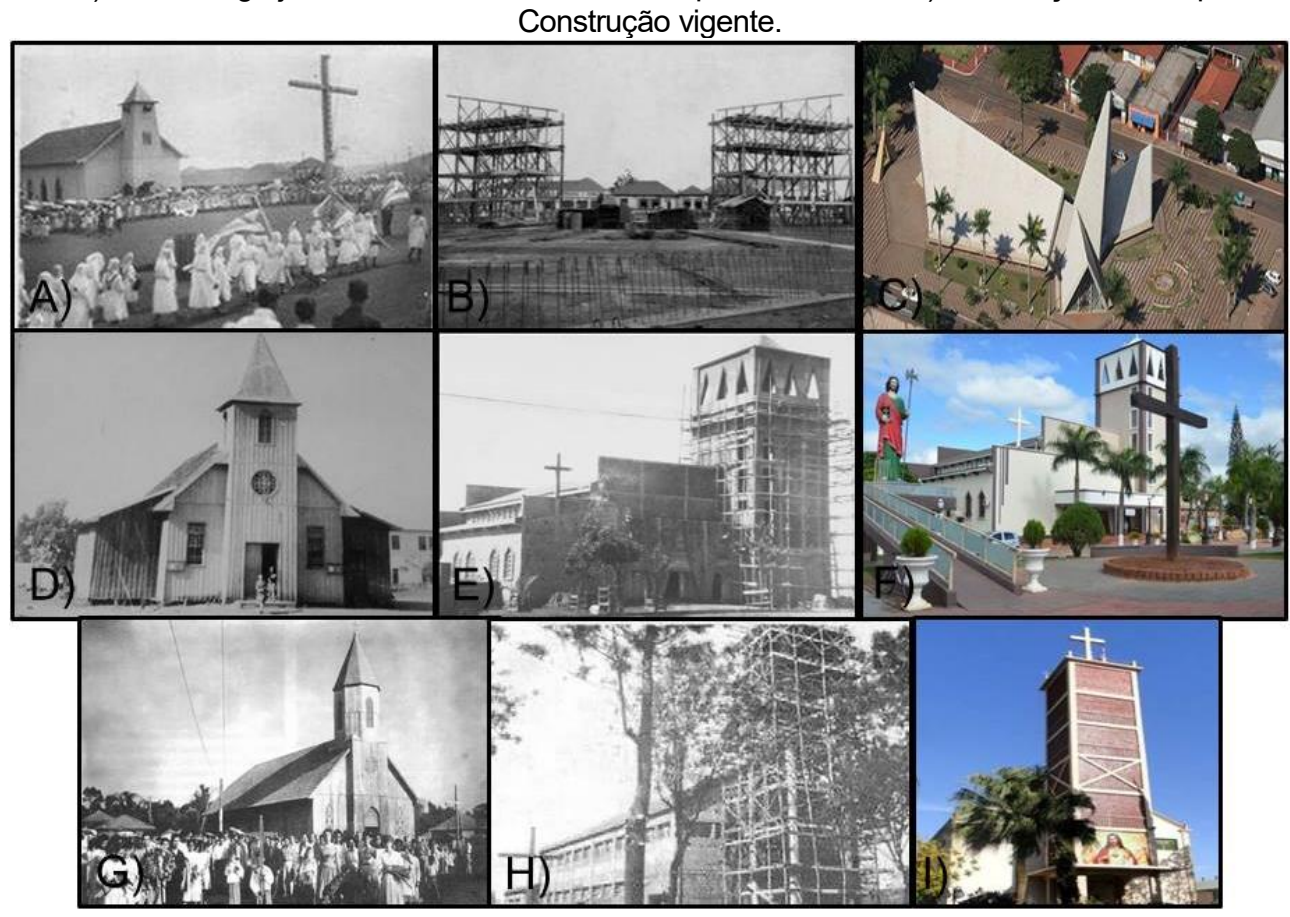

Fonte - Prefeitura Municipal de São Jorge do Ivaí, Terra Boa e Jussara (2017).

Embora as igrejas matrizes de ambos os municípios estudados preservem a localização original, estando muito próximas de outras edificações que abrigam serviços bastante relevantes para o funcionamento do município como prefeitura, correios, bancos e comércios em geral, na figura 5 notase que houve ampliação, alteração no estilo arquitetônico e mudança nos materiais utilizados na construção.

Nas imagens que representam as primeiras edificações (figura 5. A; 5. D e 5. G) as fachadas apresentam-se bastante similares. Os telhados eram caracterizados pela disposição em duas águas - vertentes que dão vazão as águas pluviais -, a torre sobressaia na posição central, onde se localizava a entrada. Janelas de vidro estavam presentes nas três igrejas, entretanto, elementos ornamentais como a rosácea - abertura circular fechada por vitral, assentada acima do portal da fachada e que, assim como as janelas, permitiam a entrada de luz - apareciam somente nas igrejas de Terra Boa e Jussara (figura 5. D e 5. G).

Nas imagens que mostram as edificações em sua configuração atual (figura 5. C; 5. F e 5. I) verificase uma variedade no estilo arquitetônico. No caso do município de Terra Boa (figura 5. F) a torre foi deslocada para a lateral, já no município de Jussara (figura 5. I) ela permanece na parte central. No município de São Jorge do Ivaí (figura 5. C) a igreja distingue-se pela arquitetura arrojada, destoando das demais. 
Concebidas inicialmente em madeira, produto abundante na época do surgimento dos municípios estudados, as construções iam sendo modificadas à medida que as cidades cresciam. A mudança dos materiais - marcadamente da madeira para a alvenaria e a pintura externa e interna -, das formas e dos modelos utilizados na construção de residências, comércios, instituições públicas e privadas e, no caso exemplificado, de templos religiosos, assinalam a presença e uma sociedade predominantemente urbana. Novos métodos de construção e tipos de habitação refletem outras maneiras de ver o mundo e outros sistemas de valores que se estabelecem. A modificação das igrejas matrizes, ainda hoje consideradas pelos moradores como uma das principais construções presentes nos municípios estudados, marca não apenas a importância desta edificação para a comunidade, mas a necessidade de que elas representassem a nova fase pela qual os municípios passavam.

A erradicação do café, a concentração de terras, a introdução de insumos agrícolas e maquinários, a expansão dos cultivos de soja e trigo, o aumento da área destinada à pecuária, a política de crédito agrícola voltada às culturas de exportação, e finalmente, as constantes geadas, foram os fatores que, se desenvolvendo desde 1960, tiveram seus efeitos sentidos no início da década de 1970. Desta ação modernizadora do campo, quando a agricultura ficou subordinada a dinâmica industrial, formouse o chamado Complexo Agroindustrial (CAI).

Segundo Hespanhol (1990, p. 117), o processo de modernização da agricultura provocou, além de mudanças técnicas e econômicas:

[...] transformações sociais e espaciais no Estado do Paraná, materializadas através de: a) diminuição da população residente na zona rural e consequente ampliação do movimento de urbanização; b) concentração fundiária; c) retração das categorias de produtores não-proprietários; d) transformações no espaço geográfico, derivadas da instalação de modernos equipamentos de infraestrutura.

Alguns dos elementos presentes no início da colonização Norte paranaense ainda subsistem no tempo e na paisagem tanto rural quanto urbana. São construções, na maioria das vezes abandonadas, e que persistem onde a especulação imobiliária ainda não é tão intensa. Marcos que testemunharam o período do ciclo cafeeiro que foi sendo encerrado à medida que outras culturas iam sendo incorporadas, esses elementos aos poucos esmaecem e dão lugar a novos componentes que surgem na paisagem.

[...] transparece nítida ainda na paisagem de muitas áreas do antigo norte cafeeiro, os vestígios de um passado mais rico, dinâmico, cheio de vida em contraste com o quadro atual. Vastos talhões de terra trabalhados pela máquina, mas vazios de homens (ALEGRE e MORO, 1986, p.59).

A infraestrutura destinada à produção cafeeira foi sendo abandonada e substituída por uma mais adequada às novas atividades econômicas que passaram a dominar na paisagem rural e urbana do Norte paranaense. As imagens apresentadas na figura 6 comprovam que o processo de modernização da agricultura implicou na composição de uma nova infraestrutura no campo e no avanço da produção de commodities, o que refletiu na organização do espaço e consequentemente na paisagem rural e urbana do Norte do estado.

A figura 6 exemplifica este tipo de alteração ocorrida na área rural.

Figura 6 - Evolução das construções destinadas ao armazenamento de grãos. A) Paiol. B) Silos.

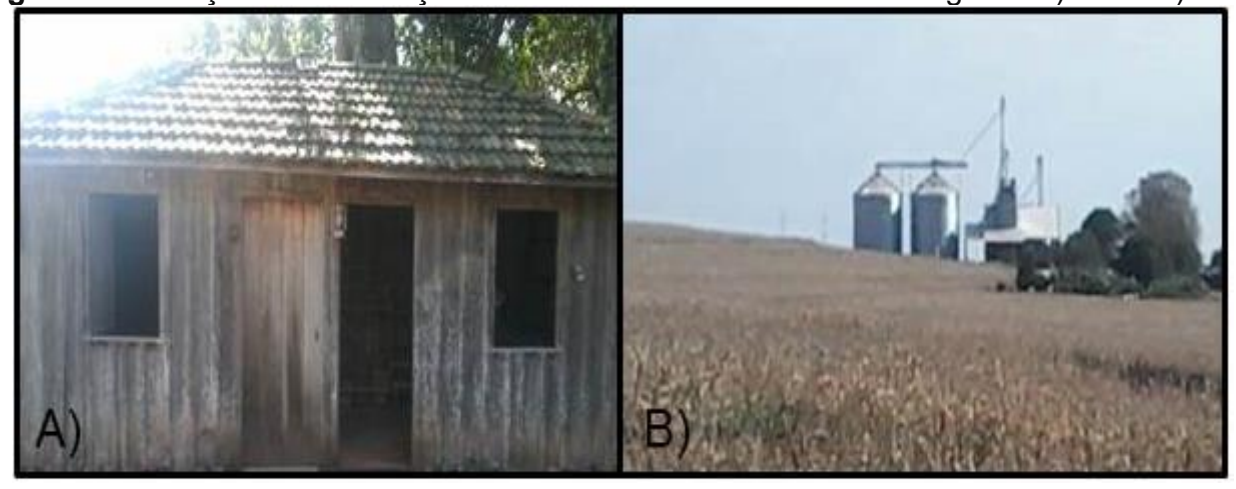

Fonte - A autora (2017) 
Embora na área rural a mudança nas edificações seja justificada pela substituição de culturas agrícolas e pela maior presença do capital no campo, na cidade, de acordo com informações dos entrevistados, há certa pressão para que os estabelecimentos comerciais e as residências em madeira sejam substituídos por construções em alvenaria, pois muitos veem estas edificações, mesmo em bom estado de conservação, como sinônimo de atraso. "Já ouvi muito dizer que o bom mesmo é prédio, que deixa a cidade mais bonita. O povo parece que não dá valor no passado."

Os entrevistados deixaram claro que a substituição dos materiais utilizados nas construções é um caminho sem volta. Segundo eles as construções em alvenaria possuem maior resistência e durabilidade e é comum que de tempos em tempos os estilos arquitetônicos ou, nas palavras dos próprios entrevistados, "os modelos" das construções mudem. Porém, ainda segundo os entrevistados algumas construções consideradas importantes - como escolas, capelas e hotéis, por exemplo - e que ilustram a criação e evolução dos municípios poderiam ser mantidas. Principalmente os entrevistados mais idosos mostraram apreço pelas antigas construções, pois as utilizaram em algum momento.

Pelo valor histórico que as construções que ainda restam como testemunhos da formação dos municípios possuem, elas podem ser de grande valia em trabalhos de campo em Geografia que tratem do conceito de paisagem e que permitam aos estudantes dos variados níveis de ensino perceber que as transformações ocorridas ao longo do tempo são reflexos da dinâmica da natureza e das mudanças sociais, culturais, políticas e econômicas que ocorrem na sociedade. Sensibilizados para o valor dessas construções os estudantes e a população em geral podem contribuir para a sua manutenção e preservação.

\section{CONSIDERAÇÕES FINAIS}

As transformações na paisagem do Norte do Paraná no início da sua colonização, seja pela ação da companhia colonizadora que atuou na região, seja pelo estado ou por iniciativas particulares, ocorreram tendo como mola propulsora o cultivo do café, responsável por dinamizar a sociedade local daquele tempo.

Os sinais dessa época ainda encontram-se presentes tanto na paisagem urbana quanto rural. Neste trabalho foram abordados aqueles representados pelas construções necessárias àquele período, sendo tratados apenas alguns dos aspectos mais recorrentes levantados durante as entrevistas realizadas com atores que testemunharam os primórdios do Norte do Paraná.

O esforço de se reconstruir uma paisagem pretérita é válido na medida em que torna possível a compreensão do passado e sua influência no presente. Quiçá seja este o grande propósito da Geografia Cultural.

\section{AGRADECIMENTOS}

A autora agradece a CAPES/Fundação Araucária pela colaboração durante a pesquisa.

\section{REFERÊNCIAS}

ALEGRE, Marcos. MORO, Dalton Áureo. A mobilidade da população nas antigas áreas cafeeiras do norte do Paraná. Boletim de Geografia. Maringá, ano 4, n. 1, janeiro de 1986.

CLAVAL, Paul. A Geografia Cultural. Tradução de Luís Fugazzola Pimenta e de Margareth de Castro Afeche Pimenta. Florianópolis: UFSC, 2014.

COMPANHIA MELHORAMENTOS NORTE DO PARANÁ. Colonização e desenvolvimento do norte do Paraná. São Paulo: Ave Maria, 1975. 
HARTUNG, Miriam Furtado. A comunidade do sutil: história e etnografia de um grupo negro na área rural do Paraná. Tese (doutorado) - Universidade Federal do Rio de Janeiro. Rio de Janeiro, 2000.

HESPANHOL, Antonio Nivaldo. O binômio soja/trigo na modernização da agricultura do Paraná: o caso dos municípios de Ubiratã, Campina da Lagoa e Nova Cantu. Rio Claro. UNESP. 1990. (Dissertação de Mestrado).

LUZ, France. O fenômeno urbano numa Zona Pioneira: Maringá. Maringá: Gráfica municipal de Maringá, 1997.

McDOWELL, Linda. A transformação da geografia cultural. In: GREGORY, Derek; MARTIN, Ron; SMITH, Graham. Geografia Humana: sociedade, espaço e ciência social. Rio de Janeiro: Jorge Zahar, 1996.

MONBEIG, P. Pioneiros e Fazendeiros de São Paulo. São Paulo: Hucitec, Polis, 1984.

PADIS, Pedro Calil. Formação de uma economia periférica: o caso do Paraná. São Paulo: Hucitec, 1981.

SANTOS, Milton. Metamorfoses do espaço habitado: fundamentos teóricos e metodológicos da geografia. São Paulo, Hucitec, 1988.

SAUER, Carl O. A morfologia da paisagem. In: CORREAA, Roberto Lobato. \& ROSENDAHL, Z. (Org.) Paisagem, tempo e cultura. 2. ed. Rio de Janeiro: EdUERJ, 2004.

Foreword to History Geography. In: LEIGHLY, J. Land and Life: a selection from the $\overline{\text { writings }}$ of Carl Ortwin Sauer. Berkeley: University of California Press, 1983.

Geografia Cultural: In: CORREAA, R. L.; ROSENDAHL, Z. (Orgs.). Introdução a Geografia Cultural. Rio de Janeiro: Bertrand Brasil, 2003.

RAPOPORT, Amos. House form and culture. Prentice-Hall, Inc. Englewood Cliffs, N.J., USA, 1969.

TOMAZI, Nelson Dacio. Construções e silêncios sobre a $(R e)$ ocupação da região norte do estado do Paraná. In: Maringá e o norte do Paraná (Estudos de história regional) Reginaldo Benedito Dias e José Henrique Rollo Gonçalves (organizadores). Maringá: EDUEM, 1999.

WACHOWICZ, Ruy Chistovam. História do Paraná. 9. ed. Curitiba: Imprensa Oficial do Paraná, 2001.

Recebido em: 23/02/2018

Aceito para publicação em: 22/05/2018 